\title{
Analisis Pengaruh Media Pendingin Terhadap Kekerasan Baja S45C Pada Proses Hardening-Tempering
}

\author{
Alfian Siswara Arlingga*, Somawardi, Sugianto \\ Teknik Mesin \& Manufaktur, Teknik Mesin, Politeknik Manufaktur Negeri Bangka Belitung \\ *alfiansantos17@gmail.com
}

\begin{abstract}
This study used an experimental method, in the form of the heat treatment hardening $930^{\circ} \mathrm{C}$ with the variations in the cooling media of the coconut water, table salt water, mineral waterwater, coolant radiator, and dromus water and variations in temperatures of tempering $200^{\circ} \mathrm{C}, 420^{\circ} \mathrm{C}$, and $600^{\circ} \mathrm{C}$, the specimens were cylindrical in diameter $25 \mathrm{~mm}$ and $20 \mathrm{~mm}$ in length, this study aims to determine the optimum hardness value of S45C steel specimens due to the heat treatment process hardening-tempering.

From the results of the study, there is the effect of hardening $930{ }^{\circ} \mathrm{C}$ there is the most optimal hardness value found in coconut water cooling media with the hardness level of 53.5 HRC. Under the influence of tempering $200^{\circ} \mathrm{C}$ there is the optimum hardness value found from the influence of mineral water cooling media with the hardness level of $50.7 \mathrm{HRC}$, while the influence of tempering $420^{\circ} \mathrm{C}$ there is the most optimal hardness value from the influence of mineral water cooling media with the hardness level of $41.8 \mathrm{HRC}$, and for tempering effect $600^{\circ} \mathrm{C}$ there is the most optimal hardness value available from the influence of the coconut water cooling media with the hardness level of $35.93 \mathrm{HRC}$.
\end{abstract}

Keywords : hardening, tempering, S45C steel, hardness

\section{PENDAHULUAN}

Dalam era industri saat ini baja secara umum sangatlah sering digunakan dalam berbagai kegiatan industri baik dalam pembuatan komponen mesin, proses produksi peralatan produksi. Baja mempunyai ketahanan aus dan gesekan yang kurang baik, oleh karena itu perlu adanya perlakuan khusus untuk meningkatkan sifat-sifat mekanik permukaan material terutama yang berkaitan dengan ketahanan aus dan gesekan yaitu kekerasan permukaan material. Sebagai salah satu contoh adalah baja yang digunakan dalam poros roda traktor tangan yang memerlukan proses heat treatment agar poros tersebut lebih kuat dan tahan lebih lama pada usia pakai.

Peningkatan kekerasan baja biasanya menggunakan proses perlakuan panas (heat treatment). Perlakuan panas adalah suatu proses pemanasan dan pendinginan baja dalam keadaan padat untuk mengubah sifat-sifat fisis baja tersebut. Baja dapat dikeraskan hingga tahan aus dan kemampuan memotong meningkat, atau baja dapat dilunakan untuk mempermudah permesinan lebih lanjut [1].

Proses hardening berguna untuk memperbaiki kekerasan dari baja tanpa mengubah komposisi kimia secara keseluruhan. Beberapa kasus, proses hardening banyak dilakukan pada material baja. Material baja memiliki sifat hardenability dengan adanya sifat ini pada material baja dapat dikeraskan dengan pembentukan martensite [2].

Proses hardening pada baja karbon sedang dapat menghasilkan sifat mekanik yang lebih kuat dari pada sebelumnya, karena perubahan fasa pada baja tersebut. Sebagai 
contoh baja S45C perubahan fasa austenite menjadi fasa martensite, dimana fasa austenite ini fasa yang tidak stabil pada suatu baja dan perlu dilakukan perlakuan lain untuk mendapatkan sifat mekanik baja yang lebih baik, sedangkan fasa martensite adalah fasa yang terbentuk dari pendinginan cepat dan menghasilkan sifat yang sangat keras dan getas pada baja, biasanya pada tahap pemanasan ini baja tidak bisa sepenuhnya digunakan [2].

Baja yang telah dikeraskan bersifat rapuh dan tidak cocok untuk digunakan, setelah melalui proses tempering kekerasan dan kerapuhan dapat diturunkan sampai memenuhi persyaratan penggunaan. Kekerasan turun, kekuatan tarik akan turun pula sedangkan keuletan dan ketangguhan baja akan meningkat [3].

Faktor yang mempengaruhi kekerasan baja pada proses hardening dan tempering adalah temperatur, holding time (waktu penahanan) dan laju pendinginan. Laju pendinginan ini dihasilkan dari proses pendinginan pada media pendingin secara cepat atau metode quenching. Media pendingin yang digunakan dalam proses quenching antara lain air kelapa, air garam dapur, air mineral, air radiator coolant, dan dromus air akan memiliki nilai kekerasan yang berbeda karena disebabkan oleh viskositas (kekentalan), densitas (massa jenis) dan temperatur yang berbeda.

Salah satu penggunaan baja dalam kegiatan produksi adalah pembuatan poros roda traktor tangan yang menggunakan baja paduan menengah. Baja S45C adalah salah satu jenis baja yang digunakan sebagai bahan pembuatan poros roda traktor tangan.

Dalam penelitian ini permasalahan yang perlu dikaji adalah berapa nilai kekerasan permukaan yang optimum terhadap kekerasan dari spesimen baja S45C setelah proses perlakuan panas hardening-tempering dengan media pendingin cepat yang digunakan yaitu air kelapa, air garam dapur, air mineral, air radiator coolant, dan air dromus.

\section{METODE PENELITIAN}

\subsection{Rancangan Penelitian}

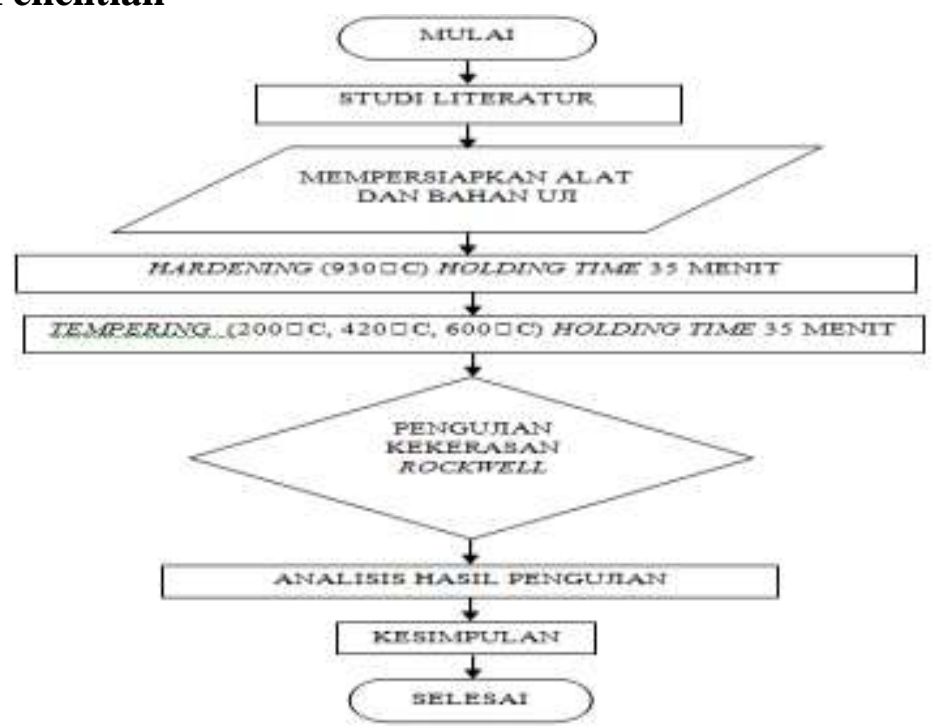

Gambar 1. Flowchart Penelitian

\subsection{Variabel Penelitian}

\subsubsection{Variabel bebas}

Variabel bebas yang digunakan pada penelitan ini adalah proses hardening dengan temperatur $930^{\circ} \mathrm{C}$ dengan mengunakan media pendingin air kelapa, air garam 
dapur, air mineral, air radiator coolant, air dromus.

\subsubsection{Variabel terikat}

Variabel terikat pada penelitian ini yaitu pada kekerasan permukaan pada baja S45C.

\subsubsection{Variabel kontrol}

a. Dimensi spesimen adalah $\emptyset=25 \mathrm{~mm}, \mathrm{P}=20 \mathrm{~mm}$.

b. Holding time pada proses hardening selama 35 menit mengunakan media pendingin celup cepat air kelapa, air garam dapur, air mineral, air radiator coolant, air dromus.

c. Suhu tempering yang digunakan adalah $200^{\circ} \mathrm{C}, 420{ }^{\circ} \mathrm{C}, 600^{\circ} \mathrm{C}$ dengan holding time selama 35 menit menggunakan media pendingin suhu kamar.

d. Beban pengujian kekerasan rockwell sama untuk setiap spesimen uji yaitu 150-kgf.

\subsection{Metode Pengumpulan Data}

\subsubsection{Desain eksperimen}

Hasil observasi dan pengumpulan data dari beberapa sumber, maka dilakukan eksperimen perlakuan panas hardening dan tempering dengan pendingin air kelapa, air garam dapur, air mineral, air radiator coolant, dan dromus air. Tujuannya untuk mengetahui besarnya pengaruh hardening terhadap sifat kekerasan permukaan yang dihasilkan dan seberapa besar pengaruh tempering terhadap sifat kekerasan permukaan yang dihasilkan. Metode pengambilan data yang digunakan dalam penelitian ini adalah metode eksperimen dengan melakukan proses pengujian langkah - langkahnya sebagai berikut :

a. Persiapan alat dan bahan pengujian

Bahan uji yang digunakan yaitu baja S45C yang berbentuk silinder. Baja S45C yaitu baja karbon menengah dengan komposisi unsur kimia yang terdapat dari sertifikat pembelian material baja S45C yaitu.

Tabel 1. Komposisi Unsur Kimia Baja S45C

\begin{tabular}{lcc}
\hline & \multicolumn{2}{c}{ Komposisi } \\
\cline { 2 - 3 } & Name & Proportion \\
\hline 1 & Carbon $(\mathrm{C})$ & $0,46 \%$ \\
\hline 2 & Silicon $(\mathrm{Si})$ & $0,23 \%$ \\
\hline 3 & Mangan $(\mathrm{Mn})$ & $0,72 \%$ \\
\hline 4 & Fosfor $(\mathrm{P})$ & $0,010 \%$ \\
\hline 5 & Sulfur $(\mathrm{S})$ & $0,010 \%$ \\
\hline 6 & Chromium $(\mathrm{Cr})$ & $0,36 \%$ \\
\hline 7 & Nickel $(\mathrm{Ni})$ & $0,10 \%$ \\
\hline 8 & Cupprum $(\mathrm{Cu})$ & $0,02 \%$. \\
\hline
\end{tabular}

b. Pembuatan spesimen

Dalam pembuatan spesimen, bahan uji dipotong menggunakan mesin gergaji potong dengan dimensi spesimen $\varnothing=25 \mathrm{~mm}, \mathrm{P}=20 \mathrm{~mm}$ sebanyak 21 benda uji. Pada setiap benda uji terdapat perlakuan yang berbeda. Perlakuan panas hardening dengan pendinginan air kelapa dilakukan pada 4 benda uji dan akan dilakukan pemanasan lebih lanjut pada 3 benda uji pemanasan tempering, air garam dapur dilakukan pada 4 benda uji dan akan dilakukan pemanasan lebih lanjut pada 3 benda uji pemanasan tempering, air mineral dilakukan pada 4 benda 
uji dan akan dilakukan pemanasan lebih lanjut pada 3 benda uji pemanasan tempering, air radiator coolant dilakukan pada 4 benda uji dan akan dilakukan pemanasan lebih lanjut pada 3 benda uji pemanasan tempering, dan air dromus dilakukan pada 4 benda uji dan akan dilakukan pemanasan lebih lanjut pada 3 benda uji pemanasan tempering. Pada 1 benda uji tidak dilakukan perlakuan karena sebagai pembanding.

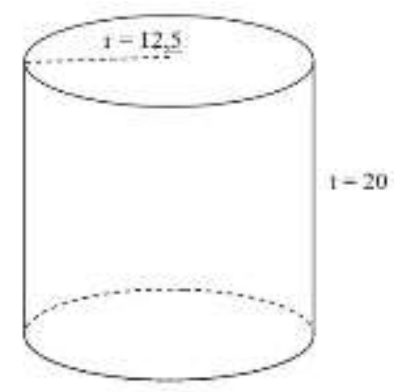

a.

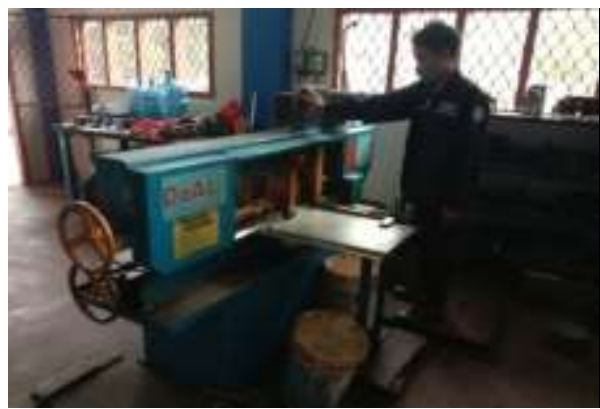

b.

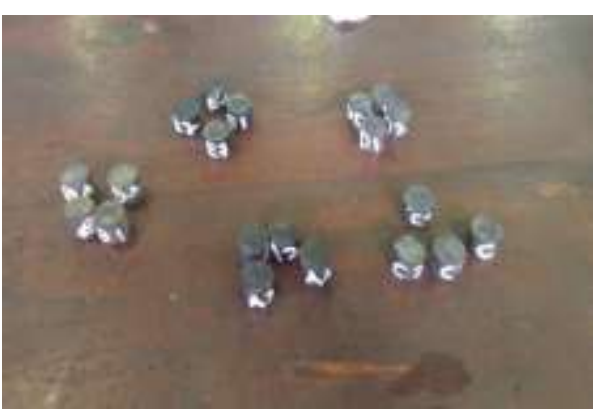

c.

Gambar 2. a. Sketsa gambar uji b. Pemotongan benda uji c. Benda uji

\section{c. Proses hardening}

Pada proses hardening temperatur yang digunakan harus diatas suhu austenite atau diatas suhu $723^{\circ} \mathrm{C}$. Pada penelitian ini peneliti menggunakan suhu $930^{\circ} \mathrm{C}$ untuk mencapai suhu austenite. Pada gambar 3 dibawah ini sebelum mencapai suhu $930^{\circ} \mathrm{C}$ peneliti melakukan penahan suhu $600^{\circ} \mathrm{C}$ terlebih dahulu untuk menghindari terjadinya keretakan pada sampel akibat adanya shock temperature.

Pada penahanan waktu (holding time) peneliti menggunakan rumus :

$$
\mathrm{T}=1,4 \times \mathrm{H}
$$

Dengan : $\mathrm{T}=$ waktu penahanan (menit)

$$
\mathrm{H}=\text { tebal benda kerja }(\mathrm{mm})
$$

Benda uji dengan diameter $=25 \mathrm{~mm}$ dan panjang $=20 \mathrm{~mm}$

$$
\mathrm{T}=1,4 \times 25=35 \text { menit }
$$

Jadi peneliti menggunakan penahanan waktu 35 menit agar mendapatkan kekerasan yang maksimal dari suatu material pada proses hardening dengan menahan temperatur pengerasan dan memperoleh pemanasan yang homogen.

Untuk proses pendinginan benda uji yang telah dilakukan perlakuan panas hardening ini, akan dicelupkan ke media pendingin secara cepat agar permukaan benda uji menjadi keras maksimal. Untuk penggunaan media pendingin yaitu air kelapa, air garam dapur, air mineral, air radiator coolant, air dromus. 


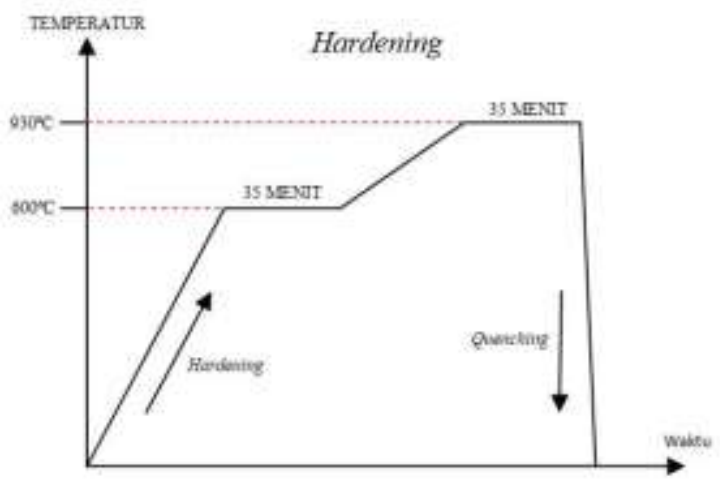

Gambar 3. Diagram pemanasan hardening dan quenching

\section{d. Proses tempering}

Pada proses tempering ini dilakukan pada saat setelah hasil dari proses hardening, temperatur yang digunakan harus dibawah suhu $723^{\circ} \mathrm{C}$. Pada penelitian ini peneliti menggunakan 3 variasi suhu tempering yaitu $200^{\circ} \mathrm{C}, 420^{\circ} \mathrm{C}, 600^{\circ} \mathrm{C}$. Proses tempering ini berguna untuk mengurangi tegangan sisa akibat dari proses perlakuan panas hardening.

Pada penahanan waktu (holding time) peneliti menggunakan rumus :

$$
\mathrm{T}=1,4 \times \mathrm{H}
$$

Dengan : $\mathrm{T}=$ waktu penahanan (menit)

$$
\mathrm{H}=\text { tebal benda kerja }(\mathrm{mm})
$$

Benda uji dengan diameter $=25 \mathrm{~mm}$ dan panjang $=20 \mathrm{~mm}$

$$
\mathrm{T}=1,4 \times 25=35 \text { menit }
$$

Jadi peneliti menggunakan penahanan waktu 35 menit agar memperoleh pemanasan yang homogen. Proses pendinginan pada 3 variasi pemanasan tempering ini yaitu suhu kamar.

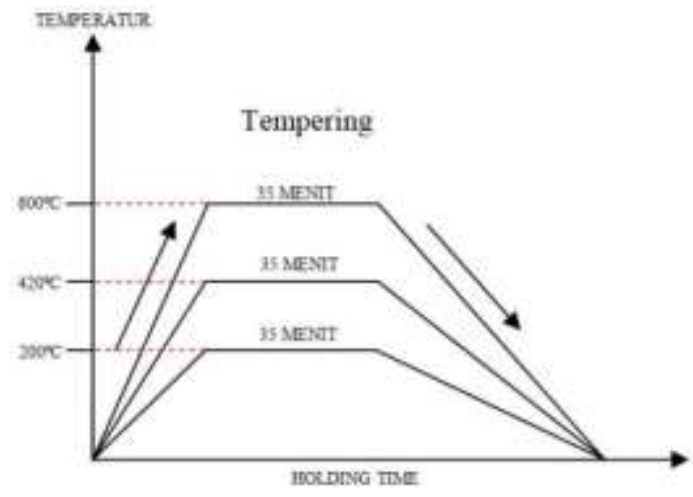

Gambar 4. Diagram pemanasan tempering

e. Pengujian

f. Mengumpulkan / mencatat semua data dan hasil pengujian. 
Tabel 2. Lembar pengamatan pengujian kekerasan hardening-tempering

\begin{tabular}{|c|c|c|c|c|c|c|c|c|c|c|c|c|c|c|c|c|c|c|}
\hline \multirow{4}{*}{ Naterial } & \multicolumn{17}{|c|}{ Hasil Kekerasan HaC } & \multirow{4}{*}{ Pendinginan } \\
\hline & \multirow{3}{*}{$\begin{array}{l}\text { Tenpa } \\
\text { Perlakvan }\end{array}$} & \multicolumn{16}{|c|}{ Perlakuan Panas } & \\
\hline & & \multicolumn{4}{|c|}{ Handering $930^{\circ} \mathrm{C}$} & \multicolumn{4}{|c|}{ Tempering $200^{\circ} \mathrm{C}$} & \multicolumn{4}{|c|}{ Tempering $4200^{\circ} \mathrm{C}$} & \multicolumn{4}{|c|}{ Tempering 600\%C } & \\
\hline & & 1 & 2 & 3 & Rerata & 1 & 2 & 3 & Rerata & 1 & 2 & 3 & Rerata & 1 & 2 & 3 & Rerata & \\
\hline \multirow{5}{*}{$545 \mathrm{C}$} & & & & & & & & & & & & & & & & & & Drowus Ois \\
\hline & & & & & & & & & & & & & & & & & & $\begin{array}{l}\text { Air Garm } \\
\text { DaprI }\end{array}$ \\
\hline & & & & & & & & & & & & & & & & & & Air Kelappa \\
\hline & & & & & & & & & & & & & & & & & & $\begin{array}{l}\text { Air Ronimory } \\
\text { Cooliany }\end{array}$ \\
\hline & & & & & & & & & & & & & & & & & & Air Mmeral \\
\hline
\end{tabular}

\subsection{Analisis Data}

Teknik analisis data yang dipakai dalam penelitian ini adalah metode rancangan acak lengkap (RAL) 1 faktor, data dari proses hardening dengan media pendingin yang berbeda dan proses tempering dengan variasi pemanasan yang berbeda pada benda uji akan diuji pada proses kekerasan rockwell dengan pengujian pada tiga titik permukaan yang berbeda pada setiap benda uji, maka diambil nilai pada pengujian yang dilakukan dengan menghitung rata-rata menggunakan aplikasi microsoft office excel dan dilakukan pembuatan grafik dan akan terlihat nilai kekerasan yang optimum. Dari data tersebut akan diketahui nilai optimum dari media pendingin yang dilakukan sehingga menghasilkan data yang valid dan benar agar bermanfaat pada penelitian selanjutnya.

\section{HASIL DAN PEMBAHASAN}

\subsection{Hasil}

Pada pengujian kekerasan tersebut dilakukan untuk mengetahui pengaruh perbandingan proses pendinginan terhadap kekerasan material baja S45C dengan pemanasan hardening suhu $930^{\circ} \mathrm{C}$ dan pemanasan tempering dengan 3 variasi suhu pemansan yaitu $200^{\circ} \mathrm{C}, 420^{\circ} \mathrm{C}, 600^{\circ} \mathrm{C}$. Data hasil pengujian selanjutnya diolah sehingga diperoleh kesimpulan dan menghasilkan nilai yang optimum.

Tabel 3. Hasil pengujian kekerasan pada proses hardening-tempering

\begin{tabular}{|c|c|c|c|c|c|c|c|c|c|c|c|c|c|c|c|c|c|c|}
\hline \multirow{3}{*}{ Material } & \multicolumn{17}{|c|}{ Hasil Kekerasan HRC } & \multirow{4}{*}{ Penànginar } \\
\hline & \multirow{2}{*}{$\begin{array}{c}\text { Tanpa } \\
\text { Periahuan }\end{array}$} & \multicolumn{16}{|c|}{ Periahuan Panas } & \\
\hline & & \multicolumn{4}{|c|}{ Hordbring $930^{\circ} \mathrm{C}$} & \multicolumn{4}{|c|}{ Tempering $200^{\circ} \mathrm{C}$} & \multicolumn{4}{|c|}{ Tempering $420^{\circ} \mathrm{C}$} & \multicolumn{4}{|c|}{ Tempering $600^{\circ} \mathrm{C}$} & \\
\hline \multirow{6}{*}{$545 \mathrm{C}$} & \multirow{6}{*}{12.6} & 1 & 2 & 3 & Rerata & 1 & 2 & 3 & Rerata & 1 & 2 & 3 & Rerata & 1 & 2 & 3 & Rerata & \\
\hline & & 42 & 42 & 418 & 41.93 & 402 & 39.5 & 39.8 & 39.83 & 29.4 & 30.7 & 30.3 & 30.13 & 219 & 22.6 & 228 & 22.43 & Dromis $O$ il \\
\hline & & 50 & 522 & 53.2 & 518 & 492 & 49 & 43.8 & 49 & 38.6 & 39.7 & 387 & 39 & 332 & 33.5 & 33.9 & 33.53 & $\begin{array}{l}\text { Air Garan } \\
\text { Dapur }\end{array}$ \\
\hline & & 53.5 & 54.4 & 526 & 535 & 505 & 50.9 & 50.2 & 50.53 & 41.1 & 41.7 & 419 & 4157 & 367 & 35.8 & 353 & 35.93 & Air Kalapa \\
\hline & & 49 & 47.6 & 499 & 48.83 & 472 & 47 & 47.1 & 41.57 & 36 & 372 & 36.4 & 3653 & 294 & 30 & 29.8 & 29.73 & $\begin{array}{l}\text { Air Rationter } \\
\text { Coolint }\end{array}$ \\
\hline & & 522 & 54.1 & 54 & 533 & 502 & 50.9 & 51 & 507 & 41,7 & 41.7 & 42 & 418 & 35.7 & 34.7 & 352 & 35.2 & Ar Mrneral \\
\hline
\end{tabular}

Berdasarkan data diatas bahwa proses perlakuan panas dengan media pendingin cepat menghasilkan tingkat kekerasan yang bervariasi. rata-rata dari hasil pengujian kekerasan tersebut dapat dilihat pada tabel dibawah ini. 
Tabel 4. Hasil Rata-rata Kekerasan Pada Proses Hardening-Tempering

\begin{tabular}{ccccc}
\hline Media Pendingin & $\begin{array}{c}\text { Hardening } \\
930^{\circ} \mathrm{C}\end{array}$ & $\begin{array}{c}\text { Tempering } \\
200^{\circ} \mathrm{C}\end{array}$ & $\begin{array}{c}\text { Tempering } \\
420^{\circ} \mathrm{C}\end{array}$ & $\begin{array}{c}\text { Tempering } \\
600^{\circ} \mathrm{C}\end{array}$ \\
\hline Air Kelapa & 53,2 & 50,53 & 41,57 & 35,93 \\
\hline Air Garam Dapur & 51,8 & 49 & 39 & 33,53 \\
\hline Air Mineral & 53,3 & 50,7 & 41,8 & 35,2 \\
\hline Radiator Coolant & 48,83 & 41,57 & 36,53 & 29,73 \\
\hline Air Dromus & 41,93 & 39,83 & 30,13 & 22,43 \\
\hline
\end{tabular}

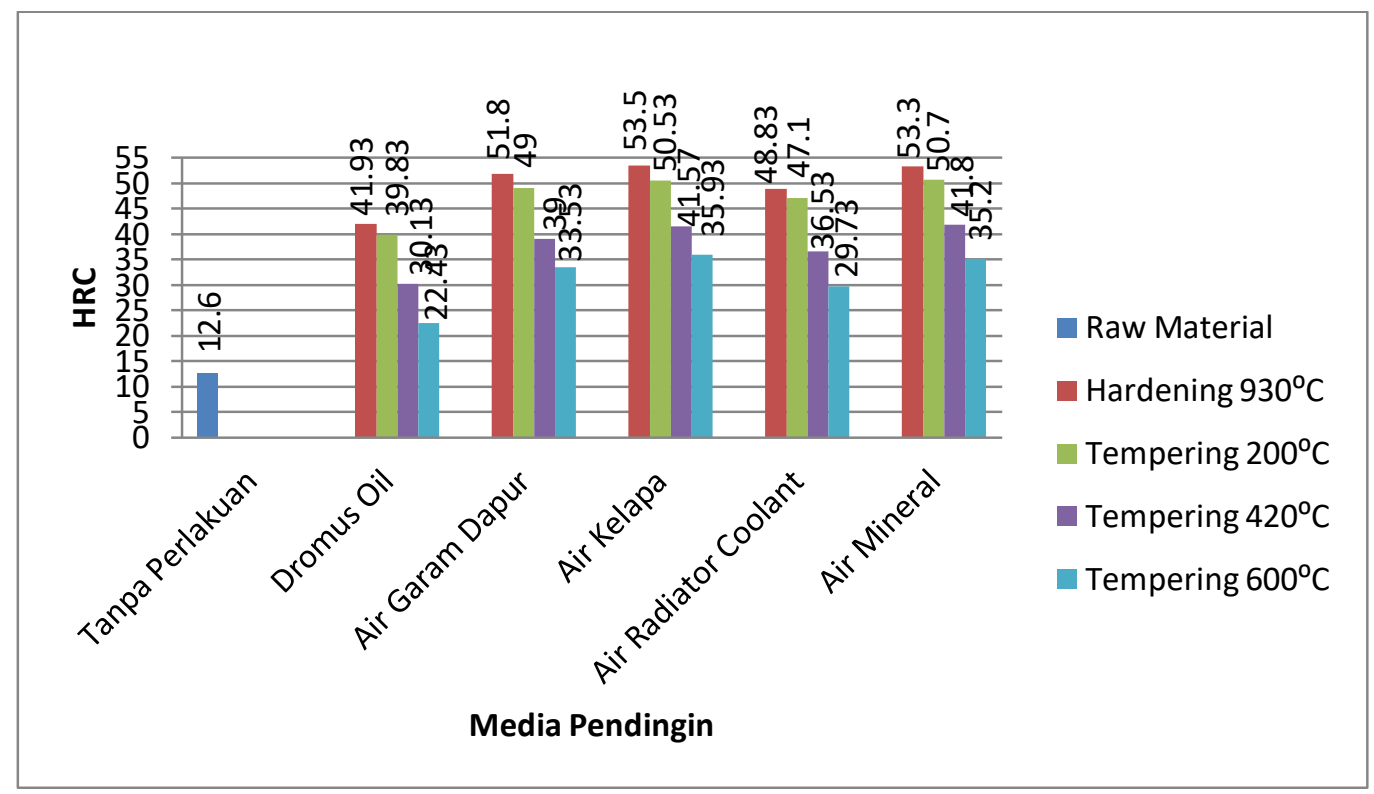

Gambar 5. Grafik nilai uji kekerasan setelah proses hardening - tempering

\subsection{Pembahasan}

\subsubsection{Kekerasan spesimen hardening $930^{\circ} \mathrm{C}$}

Pada spesimen hardening $930^{\circ} \mathrm{C}$ nilai kekerasaan yang paling tinggi terhadap benda uji tanpa perlakuan yaitu pada spesimen air kelapa dengan tingkat kekerasan 53.5 HRC, sedangkan nilai kekerasaan pada spesimen air mineral $53.3 \mathrm{HRC}$, nilai kekerasaan pada spesimen air garam dapur 51.8 HRC, nilai kekerasaan pada spesimen air radiator coolant $48.83 \mathrm{HRC}$, dan nilai kekerasaan pada spesimen dromus air 41.93 HRC. pada proses perlakuan panas hardening ini, baja tanpa perlakuan atau raw material yang berupa ferrite akan bertransformasi menjadi austenite ketika terjadi pemanasan diatas suhu austenite atau diatas suhu $723^{\circ} \mathrm{C}$, dan dilakukan pendinginan secara cepat sehingga akan terjadi perubahan menjadi martensite. Pada pengerasan ini baja akan menjadi sangat keras dan getas.

\subsubsection{Kekerasan spesimen tempering $200^{\circ} \mathrm{C}$}

Pada spesimen tempering $200^{\circ} \mathrm{C}$ nilai kekerasaan yang paling tinggi terhadap raw marerial yaitu pada spesimen air mineral dengan tingkat kekerasan 50.7 HRC, sedangkan nilai kekerasaan pada spesimen air kelapa $50.53 \mathrm{HRC}$, nilai kekerasaan pada spesimen air garam dapur $49 \mathrm{HRC}$, nilai kekerasaan pada spesimen air radiator coolant 47.1 HRC, dan nilai kekerasaan pada spesimen dromus air 39.82 HRC. Pada proses perlakuan panas hardening dengan pendinginan cepat dan dilakukan proses tempering 
rendah $\left(200^{\circ} \mathrm{C}\right)$ ini sehingga transformasi fasa berjalan lebih cepat sekali menuju martensite finish (Mf) sampai terbentuk fasa martensite temper.

\subsubsection{Kekerasan spesimen tempering $420^{\circ} \mathrm{C}$}

Pada spesimen tempering $420^{\circ} \mathrm{C}$ nilai kekerasaan yang paling tinggi terhadap raw marerial yaitu pada spesimen air mineral dengan tingkat kekerasan 41.8 HRC, sedangkan nilai kekerasaan pada spesimen air kelapa 41.57 HRC, nilai kekerasaan pada spesimen air garam dapur $39 \mathrm{HRC}$, nilai kekerasaan pada spesimen air radiator coolant 36.53 HRC, dan nilai kekerasaan pada spesimen dromus air 30.13 HRC. Pada proses perlakuan panas hardening dengan pendinginan cepat dan dilakukan proses tempering menengah $\left(420^{\circ} \mathrm{C}\right)$ ini sehingga transformasi fasa hanya masuk sampai didaerah fasa bainite dan temperatur belum cukup rendah untuk memasuki martensite star (Ms).

\subsubsection{Kekerasan spesimen tempering $600^{\circ} \mathrm{C}$}

Pada spesimen tempering $600^{\circ} \mathrm{C}$ nilai kekerasaan yang paling tinggi terhadap raw marerial yaitu pada spesimen air kelapa dengan tingkat kekerasan 35.93 HRC, sedangkan nilai kekerasaan pada spesimen air mineral 35.2 HRC, nilai kekerasaan pada spesimen air garam dapur $33.53 \mathrm{HRC}$, nilai kekerasaan pada spesimen air radiator coolant 29.73 HRC, dan nilai kekerasaan pada spesimen dromus air 22.43 HRC. Pada proses perlakuan panas hardening dengan pendinginan cepat dan dilakukan proses tempering tinggi $\left(600^{\circ} \mathrm{C}\right)$ ini sehingga terjadi transformasi austenite menjadi perlite dan pendinginan menjadi paling lambat sehingga butiran logam menjadi sangat halus, kecilkecil.

\section{KESIMPULAN}

Pada pengaruh hardening $930^{\circ} \mathrm{C}$ dengan media pendingin cepat air kelapa, air garam dapur, air mineral, air radiator coolant dan air dromus terdapat nilai kekerasan yang paling optimum terdapat pada media pendingin air kelapa dengan tingkat kekerasan 53.5 HRC. Pada pengaruh tempering $200^{\circ} \mathrm{C}$ terdapat nilai kekerasan yang paling optimum terdapat dari pengaruh media pendingin air mineral dengan tingkat kekerasan 50.7 HRC. Sedangkan pengaruh tempering $420^{\circ} \mathrm{C}$ terdapat nilai kekerasan yang paling optimum terdapat dari pengaruh media pendingin air mineral dengan tingkat kekerasan $41.8 \mathrm{HRC}$, dan untuk pengaruh tempering $600^{\circ} \mathrm{C}$ terdapat nilai kekerasan yang paling optimum terdapat dari pengaruh media pendingin air kelapa dengan tingkat kekerasan 35.93 HRC.

\section{DAFTAR PUSTAKA}

[1]. Amstead, B. H., Ostwaid, P. F., Begeman, M. L.” Teknologi Mekanik”. Diterjemahkan Sriati Djaprie. Jakarta : Erlangga, 1993.

[2]. Aldi Wahyu Permana, Ratna Dewi Anjani, \& Iwan Nugraha Gusnia, Analisa Pengaruh Variasi Media Pendingin pada Proses Heat Treatment Metode HardeningTempering Material Baja S45C terhadap Sifat Mekanik dan Struktur Mikro, Jurnal Rekayasa Mesin Vol.15, No.3, Desember 2020.

[3]. Purnomo. "Material Teknik", CV. Seribu Bintang, 2017 